\title{
A comparison between two field methods of evaluation of liquefaction potential in the Bandar Abbas City
}

\author{
Mohammad Naderi Pour*, Adel Asakereh \\ Department of Civil Engineering, University of Hormozgan, Bandar Abbas, Iran \\ Email address: \\ m.naderi2020@yahoo.com (M. N. Pour), asakereh@yahoo.com (A. Asakereh)
}

To cite this article:

Mohammad Naderi Pour, Adel Asakereh. A Comparison between Two Field Methods of Evaluation of Liquefaction Potential in the Bandar Abbas City. American Journal of Civil Engineering. Special Issue: Research and Practices of Civil Engineering in Developing Countries. Vol. 3, No. 2-2, 2015, pp. 1-5. doi: 10.11648/j.ajce.s.2015030202.11

\begin{abstract}
The geotechnical characteristics of the soil layers are one of the main factors influencing liquefaction potential of the ground. In common usage, liquefaction refers to the loss of strength in saturated, cohesionless soils due to the build-up of pore water pressures during dynamic loading. The following five screening criteria, are recommended for completing a liquefaction evaluation: Geologic age and origin, Fines content and plasticity index, Saturation, Depth below ground surface and Soil penetration resistance. The liquefaction resistance of soils can be evaluated using laboratory tests such as cyclic simple shear, cyclic triaxial, cyclic torsional shear, and field methods such as Standard Penetration Test (SPT), Cone Penetration Test (CPT), and Shear Wave Velocity (Vs). The present study is aimed at comparing the results of two field methods used to evaluate liquefaction resistance of soil, i.e. SPT and CPT. It is concluded that the liquefaction evaluation methods based on the SPT data show more conservative results compared with those based on the CPT data.
\end{abstract}

Keywords: Liquefaction Potential, Standard Penetration Test (SPT), Pore Water Pressure, Dynamic Loading

\section{Introduction}

Liquefaction is the phenomena when there is loss of strength in saturated and cohesion-less soils because of increased pore water pressures and hence reduced effective stresses due to dynamic loading. It is a phenomenon in which the strength and stiffness of a soil is reduced by earthquake shaking or other rapid loading.

A more precise definition as given by Sladen et al (1985) states that "Liquefaction is a phenomena wherein a mass of soil loses a large percentage of its shear resistance, when

subjected to monotonic, cyclic, or shocking loading, and flows in a manner resembling a liquid until the shear stresses acting on the mass are as low as the reduced shear resistance".

After initial liquefaction if large deformations are prevented because of increased undrained shear strength then it is termed," limited liquefaction" (Finn 1990).

When dense saturated sands are subject to static loading they have the tendency to progressively soften in undrained cyclic shear achieving limiting strains which is known as cyclic mobility (Castro 1975; Castro and Poulos 1979). Cyclic mobility should not be confused with liquefaction. Both can be distinguished from the very fact that a liquefied soil displays no appreciable increase in shear resistance regardless of the magnitude of deformation (Seed 1979).

Soils undergoing cyclic mobility first soften subjected to cyclic loading but later when monotonically loaded without drainage stiffen because tendency to increase in volume reduce the pore pressures. During cyclic mobility, the driving static shear stress is less than the residual shear resistance and deformations get accumulated only during cyclic loading. However, in layman 's language, a soil failure resulting from cyclic mobility is referred to as liquefaction.

Using the SPT data for evaluating liquefaction potential of the soil layers is nearly as long as the phenomenon was first recognized during 1964 Niigata earthquake.

Seed and Idriss (1971) developed the first experimental method based on the SPT data to evaluate the liquefaction potential of the ground during strong earthquakes.

Nevertheless, there are some deficiencies and shortcomings with the $S P T$, the most important of which can be summarized as follows:

- The repeatability of the test cannot be guaranteed.

- The soil profilecannot be detected continuously

- The pore pressure cannot be measured during the test.

- The sensitivity of the device to changing soil profile is 
sometimes poor.

- The influence of pore pressure fluctuations due to blow effects of the system on the test results cannot be considered.

- The theoretical interpretations about the test results cannot be implemented.

Although the effect of these factors on the accuracy and reliability of the test results are not the same, some of them may considerably influence the measured data. In contrast to $S P T, C P T$ is also another in situ testing device and technique that can be used for the same purpose, without having the above mentioned problems. However the complexity of the system and the more energy and time consuming of operation relative to the $S P T$, have caused it less popular and common in practice.

There are some initial requirements for each site to be under consideration in this study.

The results of the SPT and CPT studies must have been available and the points at which these tests are carried out cannot be far from each other.

Considering these fact, some different sites in the southern parts of Iran have been selected. These sites were located on the Hormozgan province near the coastal region of the Persian Gulf. The ground in these areas is usually consisted of deposits belonging to Testiary and Quaternary geological periods. The soil layers in these sites are between sandy silts to silty sands and can be classified as fine granular soils $(P I \leq$ $5 \%$ ). The water table in these sites are between 1.5-3.0 m depths and the densification of the top layers can be categorized between medium to loose.

The seismicity of the regions is relatively high compared with other areas of the country.

\section{Effective Factors in Liquefaction}

Liquefaction is most commonly observed in shallow, loose, saturated cohesionless soils subject to strong ground motions in earthquakes. Unsaturated soils are not subject to Liquefaction because volume compression does not generate excess pore water pressure.

Since liquefaction phenomena arises because of the tendency of soil grains to rearrange when sheared, any factor that prevents the movement of soil grains will increase the liquefaction resistance of a soil deposit.

Stress history is also crucial in determining the liquefaction resistance of a soil. Over consolidated soils (i.e. the soils that have been subjected to greater static pressures in the past) are more resistant to particle rearrangement and hence liquefaction as the soil grains tends to be in a more stable arrangement.

Liquefaction resistance of a soil deposit increases with depth as overburden pressure increases. That is why soil deposits deeper than about $15 \mathrm{~m}$ are rarely found to have liquefied (Krinitzky et al.1993).

Characteristics of the soil grains like distribution of shapes, sizes, shape, composition, etc. influence the susceptibility of a soil to liquefy (Seed 1979). While sands or silts are most
Commonly observed to liquefy, gravelly soils have also been known to have liquefied.

Rounded soil particles of uniform size are mostly susceptible to liquefaction (Poulus et al.1985). Well graded soils, due to their stable inter-locking configuration, are less prone to liquefaction.

Clays with appreciable plasticity are resistant to relative movement of particles during shear cyclic shear loading and hence are usually not prone to pore water pressure generation and liquefaction.

Ishihara (1993) gave the theory that non-plastic soil fines with dry surface texture do not create adhesion and hence do not provide appreciable resistance to particle rearrangement and liquefaction. Koester (1994) stated that sandy soils with appreciable fines content may be inherently collapsible, perhaps because of greater compressibility of the fines between the sand grains.

\section{Recommended Screening Criteria for Liquefaction Potential}

The following five screening criteria are recommended for completing a liquefaction evaluation:

- Geologic age and origin. If a soil layer is a fluvial, lacustrine or aeolian deposit of Holocene age, a greater potential for liquefaction exists than for till, residual deposits, or older deposits.

- Fines content and plasticity index. Liquefaction potential in a soil layer increases with decreasing fines content and plasticity of the soil. Cohesionless soils having less than 15 percent (by weight) of particles smaller than 0.005 $\mathrm{mm}$, a liquid limit less than 35 percent, and an in situ water content greater than 0.9 times the liquid limit may be susceptible to liquefaction (Seed and Idriss, 1982).

- Saturation. Although low water content soils have been reported to liquefy, at least 80 to 85 percent saturation is generally deemed to be a necessary condition for soil liquefaction. The highest anticipated temporal phreatic surface elevations should be considered when evaluating saturation.

- Depth below ground surface. If a soil layer is within 50 feet of the ground surface, it is more likely to liquefy than deeper layers.

- Soil Penetration Resistance. Seed et al, 1985, state that soil layers with a normalized SPT blowcount [(N1)60] less than 22 have been known to liquefy. Marcuson et al, 1990, suggest an SPT value of [(N1)60] less than 30 as the threshold to use for suspecting liquefaction potential. Liquefaction has also been shown to occur if the normalized CPT cone resistance (qc) is less than 157 tsf (15 MPa) (Shibata and Taparaska, 1988).

If three or more of the above criteria indicate that liquefaction is not likely, the potential for liquefaction can be dismissed. Otherwise, a more rigorous analysis of the liquefaction potential at a facility is required. 


\section{Liquefaction Analysis}

If potential exists for liquefaction at a facility, additional subsurface investigation may be necessary. Once all testing is complete, a factor of safety against liquefaction is then calculated for each critical layer that may liquefy. A liquefaction analysis should, at a minimum, address the following:

- Developing a detailed understanding of site conditions, the soil stratigraphy, material properties and their variability, and the areal extent of potential critical layers. Developing simplified cross sections amenable to analysis. SPT and CPT procedures are widely used in practice to characterize the soil (field data are easier to obtain on loose cohesionless soils than trying to obtain and test undisturbed samples). The data needs to be corrected as necessary, for example, using the normalized SPT blowcount [(N1)60] or the normalized CPT. The total vertical stress (so) and effective vertical stress (so') in each stratum also need to be evaluated. This should take into account the changes in overburden stress across the lateral extent of each critical layer, and the temporal high phreatic and piezometric surfaces,

- Calculation of the force required to liquefy the critical zones, based on the characteristics of the critical zone(s) (e.g., fines content, normalized standardized blowcount, overburden stresses, level of saturation),

- Calculation of the design earthquake's effect on each potentially liquefiable layer should be performed using the site-specific in situ soil data and an understanding of the earthquake magnitude potential for the facility, and

- Computing the factor of safety against liquefaction for each liquefaction susceptible critical layer.

\section{The Liquefaction Evaluation Method Used in the Study}

Although there are different methods for evaluating liquefaction potential of the sand layers using $S P T$ and $C P T$ data, in order to avoid scattering the results, one of them which proven to be the most appropriate one, and has been used in many cases by different researchers, has been selected and used as below:

\subsection{Robertson and Wride Method}

This method is in fact based on the method, originally suggested by Seed and Idriss (1971). In this method the values of tip resistance of the CPT and also the number of SPT blows, are corrected in terms of the fine content according to one of the two following ways:

$$
\left(\mathrm{N}_{1}\right)_{60 \mathrm{CS}}=\mathrm{K}_{\mathrm{s}}\left(\mathrm{N}_{1}\right)_{60}
$$

In which

$$
\begin{aligned}
& \mathrm{K}_{\mathrm{s}}=0.025 \mathrm{FC}+0.875 \text { for } \quad 5 \% \leq \mathrm{FC} \leq 35 \%, \mathrm{PI} \leq 5 \% \text { \& } \\
& \mathrm{K}_{\mathrm{s}}=1 \quad \text { for } \quad \mathrm{FC} \leq 5 \%, \mathrm{PI} \leq 5 \%
\end{aligned}
$$

where $F C$ is the fines content measured from laboratory gradation tests on retrieved soil samples and $P I$ is Plasticity Index of the soil. $\left(N_{1}\right)_{60}$ is SPT blow counts corrected for overburden stress.

The tip resistance of the $C P T$ can be corrected by these equations:

$$
\left(\mathrm{q}_{\mathrm{c} 1 \mathrm{~N}}\right)_{\mathrm{cs}}=\mathrm{K}_{\mathrm{c}} \mathrm{q}_{\mathrm{c} 1 \mathrm{~N}}
$$

In which

If $\mathrm{I}_{\mathrm{c}} \leq 1.64, \mathrm{~K}_{\mathrm{c}}=1.0$

If $\mathrm{I}_{\mathrm{c}} \geq 1.64, \mathrm{~K}_{\mathrm{c}}=-0.403 \mathrm{I}_{\mathrm{c}}{ }^{4}+5.581 \mathrm{I}_{\mathrm{c}}{ }^{3}-21.63 \mathrm{I}_{\mathrm{c}}{ }^{2}+33.75 \mathrm{I}_{\mathrm{c}}-17.88$

$I_{c}$ is the soil behavior type index obtained by using an Iterative Method and $q_{c l N}$ is the cone penetration resistance corrected for overburden stress.

In the second way, which has been developed in 1997, the following equations can be used to correct the $S P T$ numbers and also the $C P T$ tip resistance, respectively.

\subsection{Seed and Idriss Method}

The following equations, developed by I.M. Idriss with assistance from H.B. Seed are recommended for correcting standard penetration resistance determined for silty sands to an equivalent clean sand penetration resistance:

$$
\left(\mathrm{N}_{1}\right)_{60 \mathrm{CS}}=\alpha+\beta\left(\mathrm{N}_{1}\right)_{60}
$$

where $\alpha$ and $\beta$ are coefficients determined from the following equations:

$$
\begin{aligned}
& \alpha=0 \quad \text { for } \quad \mathrm{FC} \leq 5 \% \\
& \alpha=\operatorname{Exp} \cdot\left[1.76-(190 / \mathrm{FC})^{2}\right] \text { for } 5 \% \leq \mathrm{FC} \leq 35 \% \quad \& \\
& \alpha=5.0 \quad \text { for } \quad F C \geq 35 \% \\
& \beta=1.0 \quad \text { for } \quad \mathrm{FC} \leq 5 \% \\
& \beta=\left[0.99-\left(\mathrm{FC}^{1.5} / 1000\right)\right] \quad \text { for } 5 \% \leq \mathrm{FC} \leq 35 \% \quad \& \\
& \beta=1.2 \quad \text { for } \quad F C \geq 35 \%
\end{aligned}
$$

$$
\left(\mathrm{q}_{\mathrm{c} 1 \mathrm{~N}}\right)_{\mathrm{CS}}=\mathrm{q}_{\mathrm{c} 1 \mathrm{~N}}+\Delta\left(\mathrm{q}_{\mathrm{c} 1 \mathrm{~N}}\right)
$$

in which

$$
\begin{aligned}
& \Delta\left(\mathrm{q}_{\mathrm{c} 1 \mathrm{~N}}\right)=\mathrm{K}_{\mathrm{CPT}}\left(\mathrm{q}_{\mathrm{clN}}\right)_{\mathrm{CS}} \\
& \Delta\left(\mathrm{q}_{\mathrm{c} 1 \mathrm{~N}}\right)=\left[\mathrm{K}_{\mathrm{CPT}} /\left(1-\mathrm{K}_{\mathrm{CPT}}\right)\right]\left(\mathrm{q}_{\mathrm{c} 1 \mathrm{~N}}\right)
\end{aligned}
$$

Where

$$
\begin{aligned}
& \mathrm{K}_{\mathrm{CPT}}=0 \quad \text { for } \quad \mathrm{AFC} \leq 5 \% \\
& \mathrm{~K}_{\mathrm{CPT}}=0.0267(\mathrm{AFC}-5) \text { for } \quad 5 \% \leq \mathrm{AFC} \leq 35 \% \quad \text { \& }
\end{aligned}
$$$$
\mathrm{K}_{\mathrm{CPT}}=0.8 \quad \text { for } \quad \mathrm{AFC} \geq 35 \%
$$

Where the $A F C$ is Apparent Fine Content, to be determined as follows:

If $\mathrm{I}_{\mathrm{c}}<1.26$ apparent fines content $(\mathrm{FC} \%)=0$ If $1.26 \leq \mathrm{I}_{\mathrm{c}} \leq 3.5$ apparent fines content $(\mathrm{FC} \%)=1.75 \mathrm{I}_{\mathrm{c}}{ }^{3.25}-3.7$ If $\mathrm{I}_{\mathrm{c}}>3.5$ apparent fines content $(\mathrm{FC} \%)=100$

This method has been used in the present study.

\section{Comparison between Analysis Results}

The comparison between the results of analysis has been made in terms of calculated safety factors, based on SPT data and CPT data belong to each site under consideration.

A linear regression has been used to correlate the analysis results and the correlation factors have been considered as the 
degree of relationship between these two methods. The safety factors against liquefaction using the Robertson and Wride method [7] for all sites have been calculated and shown in Figure (1).

As can be seen the results are very scattered. In ten points the absolute differences between their safety factors are more than 1.0 (ABS> 1.0). If they are ignored, the correlation factor will increase significantly, but this factor is still very small. The above points only cover $20 \%$ of all information points, see Figure (1).

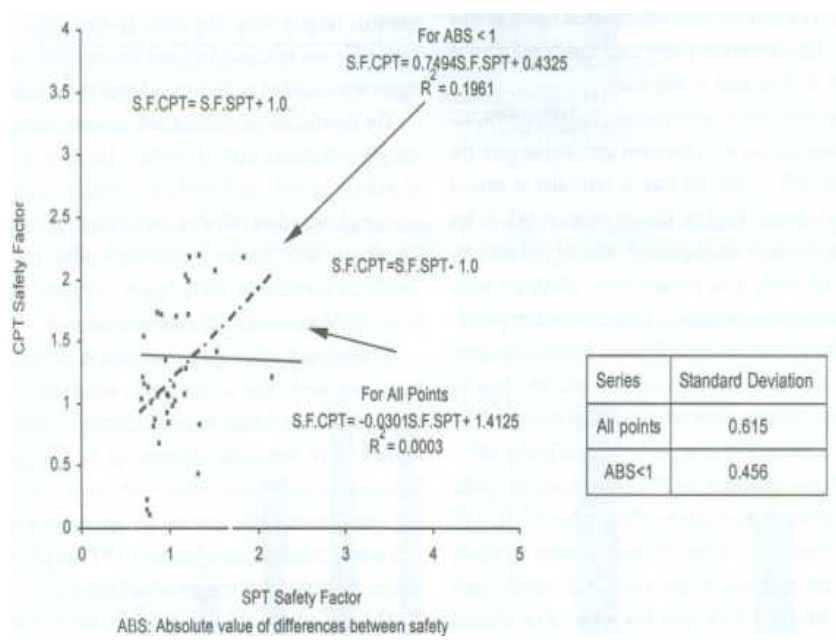

Figure 1. Comparison between safety factors against liquefaction using the method suggested by Robertson \& Wride [8].

According to the general results of this study, as far as the fine non-cohesive soils are concerned, in spite of highly scattered results, an overall conclusion can be derived, in the way that the liquefaction potential evaluation of the ground by SPT data would be more conservative (Pessimistic) than that obtained by CPT data (Optimistic), see Figure (1).

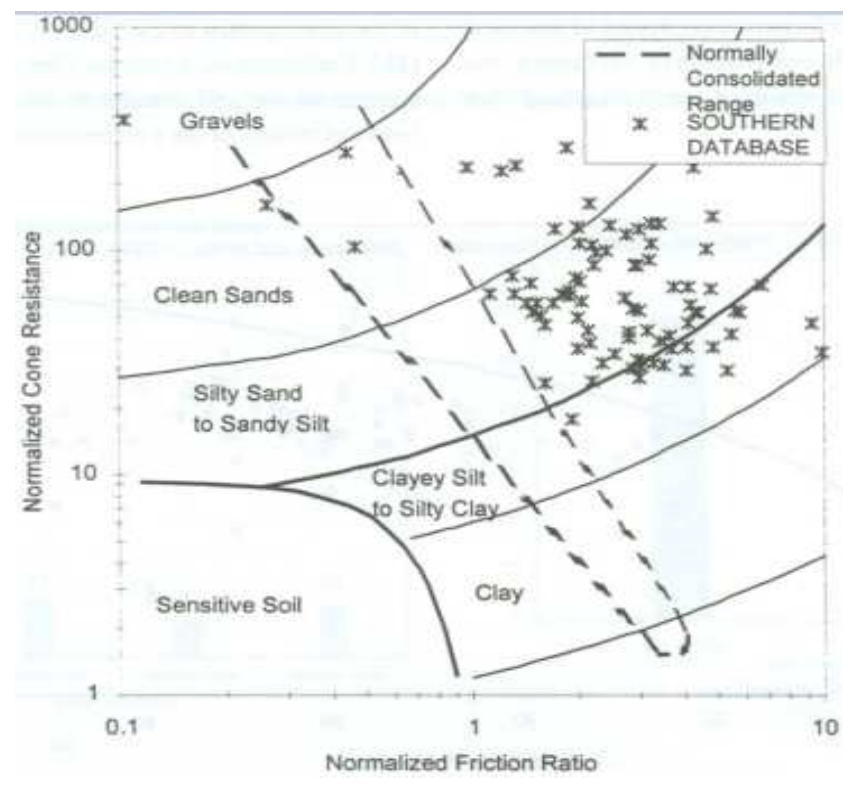

Figure 2. Soil Classification Based on CPT results.

As it was observed in this study, all sites selected were in the sandy silt to silty sand ranges, thus the results can be valid only for these fine granular soils. This classification can be also confirmed by CPT data belonging to the sites, see Figure (2).

Different researchers have focused on liquefaction potentials of susceptible soils in a comparative study by using both $S P T$ and $C P T$ of the ground layers. Among them Youd and Gilstrap [15] carried out extensive investigations to correlate between liquefaction safety factors based on CPT and SPT data of several sites. They used Robertson- Wride [7] method and obtained important results in their studies. The information points used, mainly belonged to the sites of clean sand to silty sands.

As shown in Figure (3), for $A F C>50 \%$, the suggested graphs by Robertson and Wride give the predicted $A F C$ values less than its real value in term of $I_{c}$. This is clear in Youd and Gilsrap studies as well. It has to be noted that the suggested $A F C$ - $I_{c}$ relation by Robertson-Wride is an average curve, which has been, fitted to an extensive range of many informations points.

In the comparison made between liquefaction safety factors estimated based on the $C P T$ and SPT data by Youd and Gilstrap, show also a large scattering $\left(R^{2}=0.5864\right)$, nevertheless, ignoring the points of having ABS $>0.4$ and concentrating to the $77 \%$ of the remaining points, the correlation factor would be of high value $\left(R^{2}=0.914\right)$.

The main cause of this difference between the results of Gilstrap and Youd and the results of the current study may be attributed to the quite fine nature of the selected sites in this piece of research.

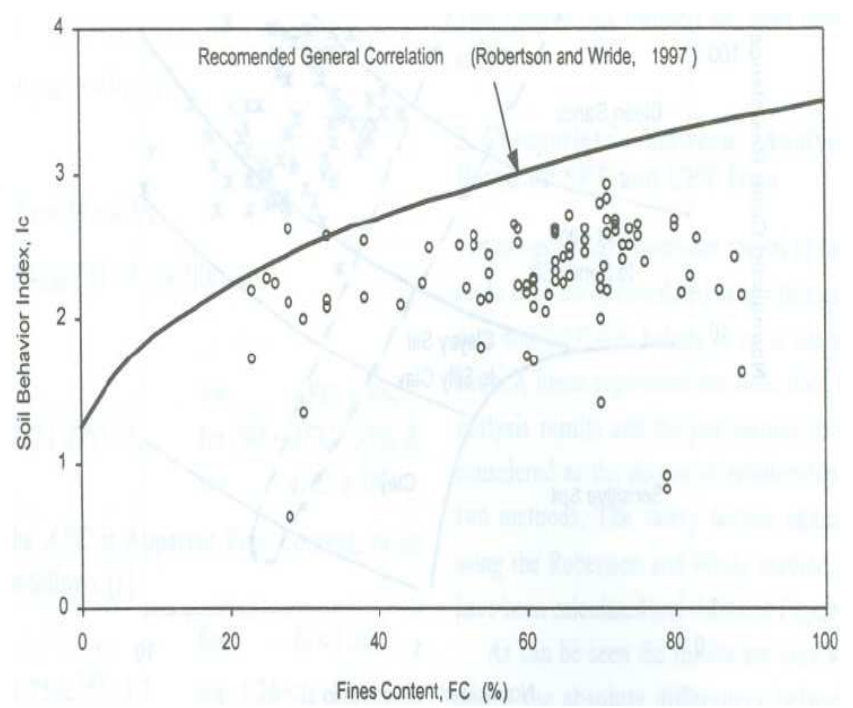

Figure 3. Correlation between fine content, $F_{c}$, of the selected sites and soil behavior index, $I_{c}$,from the closest CPT sounding.

\section{Discussion and Conclusion}

Soil liquefaction is a major concern for structures constructed with or on sandy soils. Due to the difficulty and the cost of obtaining high quality undisturbed samples, simplified methods based on in-situ tests such as the standard 
penetration test (SPT) and the cone penetration test (CPT) are preferred by geotechnical engineers for evaluation of liquefaction potential of soils.

In order to compare the liquefaction potentials based on the SPT data with those based on the CPT data, some sites in the southern parts of Iran have been selected and studied. The geotechnical characteristics of these sites have been measured both from SPT and CPT methods, and for the same seismicity condition, the liquefaction potential were estimated using the SPT and CPT based evaluation methods. At the end some correlations were derived between the obtained results and their validities were discussed and justified. Although the correlation factor was found to be very small and the results were highly scattered, it could be concluded that the liquefaction evaluation methods based on the SPT data show more conservative results compared with those based on the CPT data.

\section{References}

[1] Castro, G. (1975) "Liquefaction and cyclic mobility of saturated sands". Journal of the Geotechnical Engineering Division, ASCE, 101 (GT6), 551-569.

[2] Finn, W. L., Ledbetter, R. H., and Wu, G. "Liquefaction in silty soils: design and analysis, Ground failures under seismic conditions", Geotechnical Special Publication No 44, ASCE, Reston, 51-79, 1994

[3] Ishihara, K. (1993), "Liquefaction and Flow Failure during earthquakes (Rankine Lecture)". Geotechnique, 43 (3): 351-415, 1993

[4] Koester, J.P. (1994). "The Influence Of Fine Type And Content On Cyclic Strength" Ground Failures Under Seismic Conditions, Geotechnical Special Publication No. 44, ASCE, pp. 17-33
[5] Krinitzky et al.(1993)

[6] Poulos, S.J., Castro, G., and France, W. (1985). "Liquefaction evaluation procedure", J. Geotechnical Engineering Div., ASCE, Vol. 111, No.6, pp. 772-792.

[7] Robertson. P.K. and Wride, C.E. (1997). "Cyclic Liquefaction and its Evaluation Based on SPT and, CPT ". Final Contribution to the Proceedings of the 1996 NCEER Workshop on Evaluation of Liquefaction Resistance (T.L Youd, Chair).

[8] Robertson, P.K. and Wride, C.E. (1998). "Evaluating Cyclic Liquefaction Potential Using the Cone Penetration Test", Canadian Geotechnical Journal, 35(3), 442-459.

[9] Robertson, P.K.(1994), "suggested terminology for liquefaction”, An Internal CANLEX Report

[10] Sladen, J. A., De'Hollander, R. D., and Krahn, J. (1985),"The liquefaction of sands, a collapse surface approach", Can. Geotech. J., 22, 564- 578.

[11] Seed, H.B. and Idriss, I.M. (1971). "Simplified Procedure for Evaluating Soil Liquefaction Potential", J. of the Soil Mechanics and Foundations Division, ASCE, 97(SM9), 1249-1273.

[12] Seed, H. B. (1979). "Soil Liquefaction and Cyclic Mobility Evaluation for Level Ground During Earthquake", Journal of Geotechnical Engineering Division, ASCE, Vol 105, No. GT2, pp 201-225.

[13] Selig, E.T., and Chang C.S.(1981), "soil failure modes in undrained cyclic loading” J. Geotech. Engg. Div.,ASCE, Vol.107, No.GT5, May, pp 539-551

[14] Youd, T.L. and Idriss, I.M., eds (1997). "Proceedings of the NCEER on Evaluation of Liquefaction Resistances of Soils Tech. Report NCEER-1997-0022", Multidisciplinary Center for Earthquake Engineering Research, Buffalo, New York.

[15] Youd, T.L. and Gilstrap, S.D. (1999). "Liquefaction and Deformation of Silty and Fine Grained Soils", Procceedings $2^{\text {nd }}$ International Conference on Earthquake Geotechnical Engineering, Lisbon Portugal, 3,1013-1020. 